\title{
Metodologi Eduinnova: Pembelajaran kolaboratif yang diintegrasikan dangan teknologi untuk meningkatkan keaktifan dan interaksi siswa dalam pembelajaran daring
}

\author{
Muhammad Mahsus *, Eva Latipah \\ Universitas Islam Negeri Sunan Kalijaga Yogyakarta. \\ * Corresponding Author. E-mail: 19200010129@student.uin-suka.ac.id
}

\section{ARTICLE INFO \\ Article History: \\ Received: \\ 11 February 2021; \\ Revised: \\ 26 August 2021; \\ Accepted: \\ 07 October 2021 \\ Available Online: \\ 20 November 2021}

Keywords:

Pembelajaran

kolaboratif;

Metodologi Eduinnova;

Pembelajaran daring;

Collaborative learning;

Eduinnova

methodology;

Online learning

\begin{abstract}
Penelitian ini mengkaji inovasi pendidikan yang mengintegrasikan teknologi dalam pembelajaran kolaboratif dengan pembagian kelompok-kelompok kecil yang dikenal dengan metodologi Eduinnova. Tujuan penelitian ini untuk menambah wacana inovasi pendidikan yang diintegrasikan dengan teknologi untuk menjembatani permasalahan pembelajaran kolaboratif untuk meningkatkan inteaksi sosial siswa dengan teman dan lingkungan tanpa menghilangkan unsur pembelajaran kognitif ataupun pedagogis siswa. Analisis pembelajaran tersebut kemudian diintegrasikan dengan pembelajaran daring selama masa pandemi Covid-19. Penelitian ini merupakan penelitian kualitatif. Peneliti mengambil data dari buku dan literatur lainnya menggunakan teknik library research. Sumber data primer diambil dari buku Innovations in Educational Psychology: Perspectives on Learning, Teaching, and Human Development, karya Sternberg dan Preiss. Hasil penelitian adalah adanya kesamaan pembelajaran dengan metodologi Eduinnova dengan pembelajaran daring dalam hal penggunaan teknologi portabel sebagai media pembelajaran. Penerapan metodologi Eduinnova dalam pembelajaran daring adalah dengan memanfaatkan media zoom meeting ataupun google meet sebagai ganti dari tatap muka langsung dikelas menjadi tatap muka dalam media online. Hal ini dilakukan untuk memantau pembelajaran interaksi siswa.
\end{abstract}

This study examines educational innovations that integrate technology in collaborative learning with the division of small groups known as the Eduinnova methodology. The purpose of this study is to add to the discourse of educational innovation integrated with technology to bridge collaborative learning problems to improve student social interaction with friends and the environment without eliminating the elements of student cognitive or pedagogical learning. The learning analysis is then integrated with online learning during the Covid-19 pandemic. This research is qualitative research. Researchers took data from books and other literature using library research techniques. Primary data sources were taken from the book Innovations in Educational Psychology: Perspectives on Learning, Teaching, and Human Development, by Sternberg and Preiss. The result of this research is the similarity of learning with the Eduinnova methodology with online learning in terms of using portable technology as a learning medium. The application of the Eduinnova methodology in online learning is to use zoom media meetings or google meet instead of face-to-face in class to face-to-face in online media. This is done to monitor student interaction learning.

This is an open access article under the CC-BY-SA license.

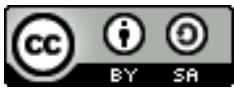

How to cite:

Mahsus, M., \& Latipah, E. (2021). Metodologi Eduinnova: Pembelajaran kolaboratif yang diintegrasikan dangan teknologi untuk meningkatkan keaktifan dan interaksi siswa dalam pembelajaran daring. Jurnal Inovasi Teknologi Pendidikan, 8(1), 1-8. https://doi.org/10.21831/jitp.v8i2.38706 


\section{PENDAHULUAN}

Teknologi memiliki peran penting dalam pembelajaran masa kini baik bagi guru maupun siswa. Teknologi dalam pembelajaran mampu memberikan fasilitas berupa ketermudahan akses informasi yang menunjang belajar bagi siswa, sedangkan bagi guru, teknologi memberikan fasilitas perangkat media pembelajaran sehingga meningkatkan kemampuan pedagogis dalam mengajar dan menciptakan pembelajaran yang interaktif dan aktif (Budiman, 2017). Terlebih dalam pembelajaran daring selama masa covid-19 ini. Ketika teknologi benar-benar dimanfaatkan oleh anak-anak untuk belajar maka akan jauh lebih efektif meningkatkan hasil belajar dan kreativitas siswa (Jochems et al., 2004). Namun anak remaja yang sudah merasakan sensasi kesenangan dan kepuasan dalam bermain gadget secara continue lebih cenderung mengalihkan perhatian mereka dalam belajar dan menyebabkan degradasi pada motivasi belajar mereka (Kurniasanti et al., 2019). Anak usia remaja dengan struktur otak pada bagian Prefrontal Cortex (PFC) yang belum matang akan lebih rentan terhadap adiksi gadget dari pada menggunakan gadget tersebut sebagai media belajar (Kurniasanti et al., 2019).

Selain berpengaruh terhadap motivasi belajar, adiksi game online juga berpengaruh pada degradasi interaksi sosial anak remaja. Penelitian yang dilakukan oleh Männikkö et al. (2015) menunjukkan adanya pengaruh negatif game online terhadap kehidupan bersosialisasi para pecandu. Suplig (2017) menjabarkan dampak tersebut berupa tindakan pemain game online yang lebih suka menyendiri dari pada bersosialisasi dengan orang lain. Apriani et al. (2020) dalam penelitianya menambahkan dampak negatif adiksi game online terhadap interaksi sosial diantaranya lebih banyak bersifat agresif serta memiliki social intelligence dan self regulation yang rendah.

Dengan demikian, guru dalam proses mengajarkan kepada murid tidak hanya berfokus pada aspek kognitif, tetapi juga perlu mencerdaskan kemampuan sosial siswa. guru dalam mengintegrasikan teknologi ke dalam proses pembelajaran daring tidak hanya dimotivasi oleh peran sentral mereka dalam dunia kerja dan pengetahuan, tetapi juga oleh potensinya sebagai mediator hubungan sosial diantara siswa. Usaha yang dapat dilakukan adalah dengan menerapkan pembelajaran interaktif dan kolaboratif dengan membagi siswa kedalam kelompok-kelompok kecil yang diintegrasikan dengan teknologi. Model pembelajaran ini dinamakan dengan pembelajaran metodologi Eduinnova. Pembelajaran ini bertujuan untuk mengubah pengalaman kelas menjadi pengalaman interaktif dan kolaboratif yang memberikan berbagai manfaat pedagogis.

Beberapa penelitian menyebutkan bahwa pembelajaran kolaboratif berpengaruh terhadap hasil belajar dan prestasi belajar siswa (Mahendra et al., 2018; Marhamah et al., 2017; Muttaqin et al., 2018). Pembelajaran kolaboratif dalam penelitian mampu meningkatkan pemahaman siswa terhadap suatu bacaan dan konsep pada siswa (Siri, 2020), karena pembelajaran ini menstimulasi keingintahuan siswa (Nurkamilah, 2017). Pembelajaran kolaboratif menjadi sebuah alternatif pembelajaran yang berpusat pada peserta didik (Susanti et al., 2017), berbeda dengan pembelajaran konvensional (Diana et al., 2019). Namun, pembelajaran kolaboratif pada masa pandemi akan sulit dilaksanakan ketika masa pandemi Covid-19 karena semua pembelajaran dilakukan dengan sistem daring.

Pembelajaran kolaboratif sudah dilakukan dalam penelitian-penelitian sebelumnya di Indonesia namun belum diintegrasikan dengan teknologi. Penelitian Umamah dan Muassomah (2020) mengintegrasikan pembelajaran kolaboratif dengan teknologi Whatsapp Group hanya saja pelaksanaannya sama dengan pembelajaran kolaboratif pada penelitian-penelitian lainnya. Penelitian pembelajaran kolaboratif dengan teknologi dilakukan oleh Tüzün et al. (2019) degan menggunakan Multi-User Virtual Environments (MUVE) tiga dimensi untuk menguji efektifitas lingkungan belajar. Berbeda dengan penelitian ini yang mengkaji inovasi pembelajaran kolaboratif menggunakan metodologi Eduinnova.

Penelitian ini mengkaji inovasi pendidikan yang mengintegrasikan teknologi dalam pembelajaran kolaboratif dalam kelompok-kelompok kecil untuk menumbuhkan jiwa sosial siswa yaitu interaksi dan kerjasama antar anggota kelompok. Pembelajaran ini dikenal dengan metodologi Eduinnova. Analisis pembelajaran tersebut kemudian diintegrasikan dengan pembelajaran daring selama masa pandemi Covid-19 untuk meningkatkan efektivitas belajar, meningkatkan pedagogis dan kemampuan interaksi sosial siswa. 
Di sisi lain, pembelajaran kolaboratif yang diintegrasikan dengan teknologi yang dikenal dengan metodologi Eduinnova belum diterapkan di Indonesia. Dengan demikian penelitian ini berusaha mendeskripsikan metodologi pembelajaran ini dan menganalisis alternatif penerapannya di Indonesia dalam pembelajaran daring di masa pandemi Covid-19. Tujuan penelitian ini untuk menambah wacana inovasi pendidikan yang diintegrasikan dengan teknologi untuk menjembatani permasalahan pembelajaran kolaboratif untuk meningkatkan inteaksi sosial siswa dengan teman dan lingkungan tanpa menghilangkan unsur pembelajaran kognitif ataupun pedagogis siswa.

\section{METODE}

Penelitian ini merupakan penelitian kualitatif, hanya saja penelitian tidak dilakukan dengan cara mengambil data dari lapangan, melainkan peneliti mengambil data dari buku dan literatur lainnya menggunakan teknik library reseacrh (penelitian kepustakaan). Data yang telah dikumpulkan diinterpretasikan dan dianalisis menggunakan pendekatan deskriptif (Creswell, 2016). Sumber data primer diambil dari buku yang dikarang oleh Preiss (2010) yang berjudul Innovations in Educational Psychology: Perspectives on Learning, Teaching, and Human Development, tentang metodologi Eduinnova yaitu pembelajaran kolaboratif dalam kelompok kecil yang diintegrasikan dengan teknologi. Kemudian dengan analysis content, peneliti menganalisis kemungkinan penerapan pembelajaran kolaboratif dengan metologi Eduinnova dengan pembelajaran daring di masa pandemi.

\section{HASIL DAN PEMBAHASAN}

\section{Sistem Kerja Metodologi Eduinnova}

Metodologi Eduinnova merupakan pendekatan pembelajaran kolaboratif kelompok kecil tatap muka yang dimediasi oleh teknologi yang bergeser dari pengaturan yang berpusat pada instruktur di mana guru memancarkan pengetahuan di depan kelas. Siswa aktif dan bekerja secara kolaboratif dalam kelompok kecil sedangkan guru bertindak sebagai mediator. Strategi pedagogis ini, yang dikenal sebagai metodologi Eduinnova, dikembangkan di Pontificia Universitas Católica de Chile selama 10 tahun. Sejak itu telah diterapkan dengan lebih dari 20.000 siswa dan 700 guru dan telah berhasil diintegrasikan di lebih dari 38 sekolah di Chili, 1 di Argentina, 8 di Brasil, dan 3 di Inggris pada berbagai tingkat pendidikan dan sosial ekonomi (Preiss, 2010).

Dasar pembelajaran kolaboratif adalah kemampuan guru dalam seleksi bahan ajar dan media yang mendukung untuk mempermudah dan meningkatkan penguasaan materi oleh siswa, sehingga kreativitas guru dalam pembelajaran ini sangat diperlukan (Ulfa et al., 2018). Langkah-langkah penerapan pembelajaran ini adalah sebagai berikut: 1.) Guru membagi siswa dalam kelas menjadi beberapa kelompok kecil secara acak; 2.) Guru memastikan semua peserta memegang perangkat seluler masing-masing; 3.) Guru menyiapkan perangkat yang dikonfigurasi khusus untuk memantau kemajuan seluruh proses, kemudian membagikan satu set pertanyaan kepada setiap siswa; 4.) Anggota kelompok harus menanggapi pertanyaan secara individu, dengan demikian bertanggung jawab untuk melakukan dan menilai pekerjaan mereka sendiri; 5.) Jawaban-jawaban tersebut kemudian dipresentasikan kepada anggota kelompok lainnya, dimana mereka akan menjalani penilaian sejawat atau kelompok lainnya; 6.) Jika para anggota tidak mencapai konsensus, sistem akan mengingatkan mereka bahwa mereka harus berkumpul pada satu tanggapan, yang memaksa mereka untuk melakukannya dengan tidak mengizinkan mereka melanjutkan ke pertanyaan berikutnya; 7.) Jika suatu kelompok memilih tanggapan yang salah sebagai jawaban konsensusnya, sistem memberi tahu mereka tentang kesalahan mereka dan memerintahkan mereka untuk mempertimbangkan alternatif lain; dan 8.) Perulangan ini berakhir saat grup akhirnya memilih alternatif respons yang tepat, di mana mereka melanjutkan ke pertanyaan berikutnya dan mengulangi prosedur yang baru saja dijelaskan sampai mereka mencapai akhir dari set pertanyaan.

Gambar 1 merupakan siklus langkah-langkah dalam penerapan pembelajaran kolaboratif. Dalam penerapan pembelajaran kolaboratif kelompok kecil dengan metodologi Eduinnova ini, terdapat beberapa hal yang perlu diperhatikan, diantaranya: 1.) Penentuan kelompok beserta anggotanya dilakukan secara acak dan berubah setiap pertemuannya; 2.) Anggota kelompok berusaha untuk 
mencapai jawaban konsensus melalui diskusi, proses yang difasilitasi oleh interaksi tatap muka dan ukuran kelompok yang kecil; 3.) Semua anggota harus berkontribusi dan berbagi gagasan terlepas dari apa yang mereka pikirkan tentang kebenaran mereka, perubahan konseptual harus berkembang dari pemahaman pelajar yang sudah ada sebelumnya dan keterlibatan aktif dalam wacana kelompok; dan 4.) Saling mendukung adalah kunci dari proses ini, karena melalui diskusi kolaboratif anggota kelompok menemukan kesalahan mereka, mengklarifikasi gagasan mereka, dan bertemu dengan jawaban baru berdasarkan pengetahuan individu dan pengalaman umum mereka.

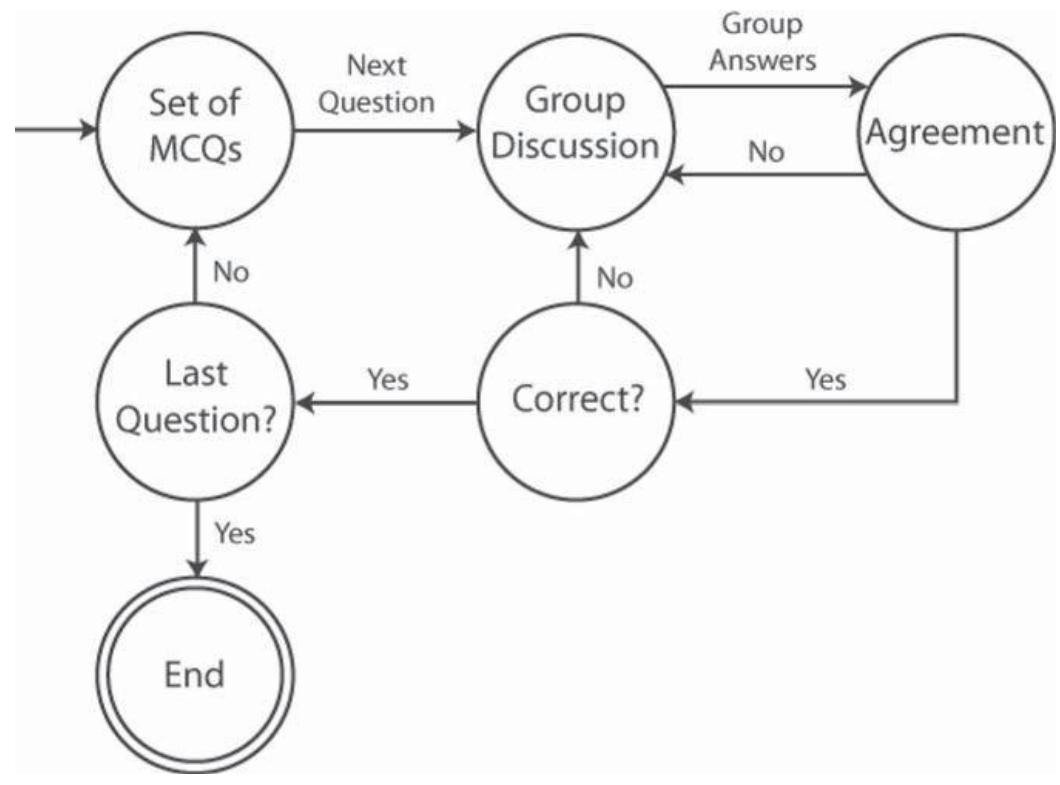

Gambar 1. Sistematika Pembelajaran Kolaboratif Kelompok Kecil dengan Metodologi Eduinnova

\section{Manfaat Metodologi Eduinnova pada Guru}

Dengan adanya pembelajaran kolaboratif dengan menggunakan metodologi Eduinnova ini, para guru akan memperoleh bebrapa manfaat. Manfaat yang pertama terkait dengan peran guru di dalam kelas yang awalnya ekspositor belajar berubah menjadi fasilitatornya. Dengan menerapkan pembelajaran ini, guru mengurangi dominasi dan intensitasnya dalam pembelajaran. Guru dalam hal ini hanya berperan sebagai mediator antar siswa dan memantau proses belajar mengajar, mengawasi kelompok siswa dan mendampingi mereka saat belajar, sehingga siswa secara mandiri berusaha berinteraksi dan menghidupkan suasana diskusi, baik dalam kelompok kecil mereka masing-masing, maupun kelompok besar diskusi dengan kelompok lain.

Hal ini mampu meningkatkan kecerdasan sosial mereka dan menekan sifat egois dan merasa paling benar sendiri karena berusaha mendengarkan pendapat atau komentar orang lain mengenai kesalahan berpikir mereka. Selain aspek kecerdasan sosial, pembelajaran kolaboratif akan menghantarkan siswa menjadi aktif dalam pembelajaran sehingga meningkatkan hasil belajar mereka (Marhamah et al., 2017). Gambar 2 merupakan alat manajemen kelas untuk memantau keaktifan siswa dalam pembelajaran kolaboratif dengan metodologi Eduinnova

Manfaat lain dari pembelajaran kolaboratif adalah guru lebih mudah menentukan intervensi terhadap problematika dalam pembelajaran kolaboratif. Penggunaan metodologi Eduinnova dijadikan alat untuk mendukung dan mendampingi tugas pedagogik. Dikarenakan ciri yang paling ditekan-kan adalah kemampuan mengikuti proses belajar siswa dan menerima penyampaian langsung hasil kegiatan. Hal ini memungkinkan untuk melakukan intervensi jika diperlukan dan memberikan umpan balik kepada siswa, sehingga meningkatkan efektivitas pembelajaran. 


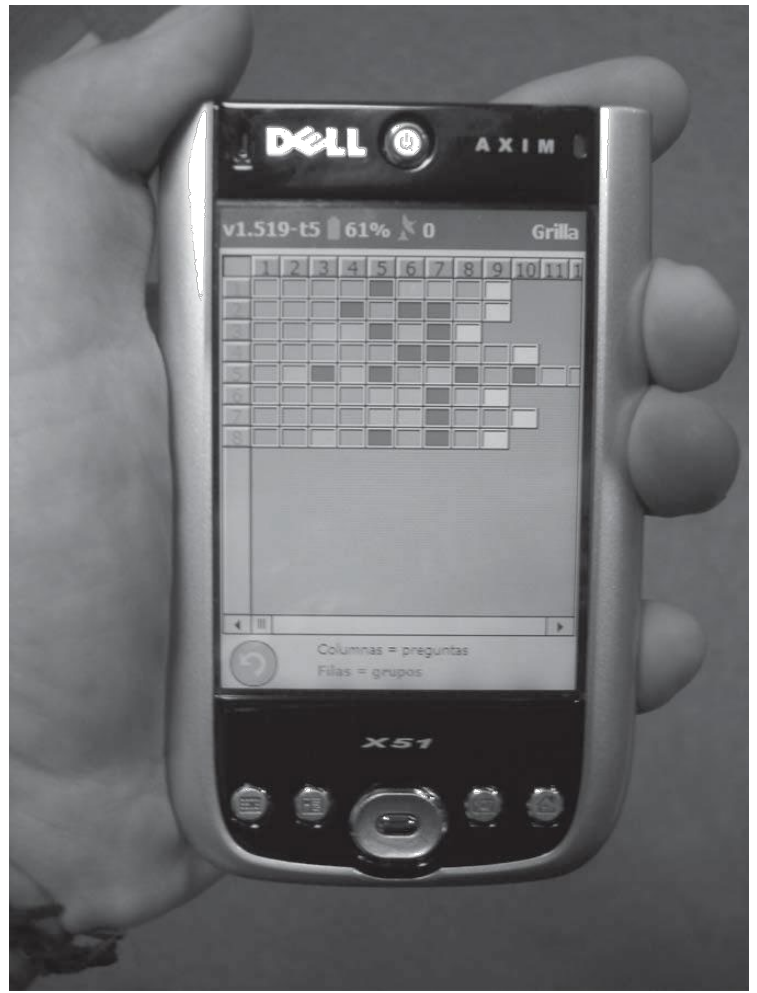

Gambar 2. Alat Manajemen Kelas untuk Memantau Keaktifan Siswa dalam Pembelajaran Kolaboratif dengan Metodologi Eduinnova

\section{Manfaat Metodologi Eduinnova Pada Siswa}

Pembelajaran kolaboratif dengan metodologi Eduinnova ini menekankan keaktifan siswa secara mandiri, sehingga dengan pembelajaran ini siswa akan mengalami perubahan dalam dirinya baik secara langsung maupun tidak langsung. Siswa yang awalnya pasif dalam pembelajaran akan mengalami perubahan peran selama kegiatan kolaboratif menjadi agen aktif dalam proses pembelajarannya sendiri. Pemimpin dan pengawas muncul secara spontan sehingga dengan adanya pola pembelajaran ini mampu meningkatkan pemahaman konsep materi pada siswa (Siri, 2020). Dengan pembelajaran ini, siswa juga mampu mengembangkan keterampilan kognitif dan sosioafektif.

Metodologi Eduinnova dalam pembelajaran ini dijadikan sebagai alat yang memfasilitasi dinamika kolaboratif dan mendorong interaksi yang toleran dan berkomitmen antara anggota kelompok. Pembentukan kelompok-kelompok beserta penentuan anggota masing-masing kelompok tersebut dibentuk secara acak, akan mendorong integrasi antara siswa yang sebelumnya tidak mengenal dan belajar antar teman sebaya (Ulfa et al., 2018). Dengan kata lain, siswa tidak hanya pandai berinteraksi dengan teman tertentu atau hanya dengan anggota kelompok mereka. Penerapan sistem acak pada gilirannya mendorong interaksi di antara mereka secara menyeluruh.

Pembelajaran ini menciptakan iklim yang berbeda dari model pembelajaran sebelumnya yang didominasi model ceramah atau techer center meskipun berbantukan media pembelajaran. Pembelajaran ini juga termasuk disiplin baru yang membutuhkan percakapan, diskusi, dan siswa untuk bertindak sebagai protagonis. Menurut Hasanuddin et al. (2019) dalam penelitiannya, adanya diskusi dan adu argumen antar siswa melatih siswa untuk berpikir secara logis, kritis dan positif. Semua hal tersebut akan menghasilkan integrasi yang lebih baik dari para siswa, yang kemudian dibawa oleh kelompok ke mata pelajaran mereka yang lain 


\section{Metodologi Eduinnova Dalam Pembelajaran Daring}

Pembelajaran dengan metodologi Eduinnova memiliki kesamaan dengan pembelajaran daring dalam hal penggunaan teknologi portabel sebagai media pembelajaran. Kelebihan dari teknologi portabel adalah kemudahan aksesnya sehingga masing-masing siswa memegang perangkat tersebut. Ketika perangkat tersebut digunakan bersama dengan desain pedagogis yang sesuai, maka hal ini menjadi sumber dukungan utama untuk pengembangan dinamika kolaboratif, memfasilitasi komunikasi antara teman sebaya dan memotivasi interaksi (Preiss, 2010).

Aspek model seluler dalam pembelajaran dengan metodologi Eduinnova ini meletakkan dasar bagi proposisi pedagogis yang menggunakan teknologi untuk mendukung proses pengajaran. Pembelajaran ini juga berdasarkan dinamika kolaboratif di mana setiap siswa memiliki akses ke komputer portabel yang cukup kecil untuk tidak menghalangi komunikasi tatap muka, sebuah pengaturan yang juga memastikan mobilitas yang diperlukan untuk memungkinkan pembentukan kelompok-kelompok kecil secara acak di dalam kelas. Hal ini dikuatkan oleh penelitian yang dilakukan oleh Santosa et al. (2020) yang menyebutkan bahwa pembelajaran kolaboratif dengan inetgrasi teknologi lebih baik dari pada pembelajaran individual dengan integrasi teknologi. Dengan demikian, dapat dipahami bahwa pembelajaran dengan metodologi Eduinnova berusaha meningkatkan pembelajaran kolaboratif dan diintegrasikan dengan teknologi portabel namun tetap mengedapkan tatap muka antara guru dan siswa, sedangkan dalam pembelajaran tatap muka secara langsung belum diperbolehkan oleh pemerintah.

Solusi yang dapat dilakukan dalam penerapan metodologi Eduinnova dalam pembelajaran daring adalah dengan memanfaatkan media Zoom Meeting ataupun Google Meet sebagai ganti dari tatap muka langsung di kelas menjadi tatap muka dalam media online. Hal ini dilakukan untuk memantau pembelajaran interaksi siswa. Adapun teknis pelaksanaan pembelajaran dengan metodologi Eduinnova dalam pembelajaran daring sama halnya dengan teknis yang disajikan pada pembahasan sebelumnya, hanya saja terkait fokus tatap muka maka alternatif yang dapat digunakan adalah dengan menggunakan Zoom Meeting atau Google Meet, sedangkan teknologi Eduinnova yang dipegang oleh guru untuk mengontrol keaktifan siswa dihubungkan dengan ponsel siswa dengan berbantukan jaringan internet.

\section{SIMPULAN}

Pembelajaran kolaboratif dengan metodologi Eduinnova meletakkan dasar bagi proposisi pedagogis dan diintegrasikan dengan teknologi untuk mendukung proses dan meningkatkan pembelajaran dalam jaringan selama masa pandemi. Pembelajaran ini juga berdasarkan dinamika kolaboratif di mana setiap siswa memiliki akses ke komputer portabel yang cukup kecil untuk tidak menghalangi komunikasi tatap muka, sebuah pengaturan yang juga memastikan mobilitas yang diperlukan untuk memungkinkan pembentukan kelompok-kelompok kecil secara acak di dalam kelas.

Manfaat yang diperoleh guru dalam pembelajaran kolaboratif dengan metodologi Eduinnova, diantaranya: 1.) Adanya perubahan peran guru di dalam kelas yang awalnya ekspositor belajar berubah menjadi fasilitator; dan 2.) Guru lebih mudah menentukan intervensi terhadap problematika dalam pembelajaran kolaboratif. Manfaat yang diperoleh siswa dalam pembelajaran kolaboratifn dengan metodologi Eduinnova, diantaranya: 1.) Siswa yang awalnya pasif dalam pembelajaran akan mengalami perubahan peran selama kegiatan kolaboratif menjadi agen aktif dalam proses pembelajarannya sendiri; dan 2.) Siswa secara mandiri berusaha berinteraksi dan menghidupkan suasana diskusi, baik dalam kelompok kecil mereka masing-masing, maupun kelompok besar diskusi dengan kelompok lain. Penerapan metodologi Eduinnova dalam pembelajaran daring adalah dengan memanfaatkan media Zoom Meeting ataupun Google Meet sebagai ganti dari tatap muka langsung dikelas menjadi tatap muka dalam media online. Hal ini dilakukan untuk memantau pembelajaran interaksi siswa. 


\section{DAFTAR PUSTAKA}

Apriani, R., Probowati, D., Indreswari, H., \& Simon, I. M. (2020). Social intelligence, love, selfregulation pada remaja yang adiksi game online jenis agresif dan non-agresif. Ilmu Pendidikan: Jurnal Kajian Teori Dan Praktik Kependidikan, 5(1), 35-42. https://doi.org/10.17977/um027v5i12020p035

Budiman, H. (2017). Peran teknologi informasi dan komunikasi dalam pendidikan. Al-Tadzkiyyah: Jurnal Pendidikan Islam, 8(1), 31-43. https://doi.org/10.24042/atjpi.v8i1.2095

Creswell, J. W. (2016). Research design: Pendekatan kualitatif, kuantitatif, dan campuran (R. K. Pancasari (trans.); 4th ed.). Pustaka Pelajar.

Diana, P. Z., Sulistiyono, R., \& Pradan, R. A. (2019). Implementasi model pembelajaran kolaboratif pada mata kuliah Bahasa Indonesia di perguruan tinggi. Bahasa: Jurnal Keilmuan Pendidikan Bahasa Dan Sastra Indonesia, 1(1), 60-70. https://doi.org/10.26499/bahasa.v1i1.27

Hasanuddin, D., Emzir, E., \& Akhadiah, S. (2019). Improving students' scientific writing ability through blended learning-based collaborative learning. International Journal of Emerging Technologies in Learning (IJET), 14(20), 34-43. https://www.learntechlib.org/p/217122

Jochems, W., Merriënboer, J. van, \& Koper, R. (2004). Integrated e-learning: Implications for pedagogy, technology and organization. RoutledgeFalmer. https://api.taylorfrancis.com/content/books/mono/download?identifierName=doi\&identifie rValue $=10.4324 / 9780203416365 \&$ type $=$ googlepdf

Kurniasanti, K. S., Assandi, P., Ismail, R. I., Nasrun, M. W. S., \& Wiguna, T. (2019). Internet addiction: A new addiction? Medical Journal of Indonesia, 28(1), 82-91. https://doi.org/10.13181/mji.v28i1.2752

Mahendra, I. W. E., Jayantika, I. G. A. N. T., \& Mintarti, N. G. P. V. (2018). Pengaruh model pembelajaran kolaboratif terhadap hasil belajar matematika dengan mengontrol bakat numerik peserta didik. Journal of Songke Math, 1(1), 26-36. http://jurnal.unikastpaulus.ac.id/index.php/jsm/article/view/369

Männikkö, N., Billieux, J., \& Kääriäinen, M. (2015). Problematic digital gaming behavior and its relation to the psychological, social and physical health of Finnish adolescents and young adults. Journal of Behavioral Addictions, 4(4), 281-288. https://doi.org/10.1556/2006.4.2015.040

Marhamah, M., Mustafa, M., \& Melvina, M. (2017). Pengaruh model pembelajaran kolaboratif berbasis Lesson Study Learning Community (LSLC). Jurnal Ilmiah Mahasiswa Pendidikan Fisika (JIMPF), 2(3), 277-282. http://www.jim.unsyiah.ac.id/pendidikanfisika/article/view/4426

Muttaqin, A., Yoesoef, A., \& Abdullah, T. (2018). Pengaruh model pembelajaran kolaboratif dengan teknik three strep interview terhadap prestasi belajar mata pelajaran sejarah siswa kelas XI SMA Negeri 1 Sigli tahun ajaran 2017/2018. JIM (Jurnal Ilmiah Mahasiswa Pendidikan Sejarah), 3(2), 17-23. http://www.jim.unsyiah.ac.id/sejarah/article/view/7667

Nurkamilah, M. (2017). Upaya meningkatkan keingintahuan matematis siswa menggunakan guided discovery learning setting kolaboratif (Penelitian tindakan kelas kelas VIII SMP Muhammadiyah 3 Depok Sleman Yogyakarta). Jurnal Theorems, 1(2), 51-63. https://doi.org/10.31949/th.v1i2.378

Preiss, D. D. (2010). Folk pedagogy and cultural markers in teaching: Three illustrations from Chile. In D. D. Preiss \& R. J. Sternberg (Eds.), Innovations in educational psychology: Perspectives on teaching, learning, and human development (pp. 325-355). Springer Publishing Company. 
Santosa, E. B., Degeng, I., Sulton, S., \& Kuwandi, D. (2020). The effects of mobile computer supported collaborative learning to improve problem solving and achievements. Journal for the Education of Gifted Young Scientists, 8(1), 325-342. https://doi.org/10.17478/jegys.656642

Siri, A. (2020). Implementasi model kolaboratif learning dalam meningkatkan pemahaman konsep siswa pada mata pelajaran sejarah kebudayaan Islam. Al-Ibrah: Jurnal Pendidikan Dan $\begin{array}{lr}\text { Keilmuan } & \text { Islam, } \\ \text { http://ejournal.stital.ac.id/index.php/alibrah/article/view/108 }\end{array}$

Suplig, M. A. (2017). Pengaruh kecanduan game online siswa SMA Kelas X terhadap kecerdasan sosial sekolah Kristen swasta di Makassar. Jurnal Jaffray, 15(2), 177-200. https://doi.org/10.25278/jj71.v15i2.261

Susanti, S., Prasetyo, T., \& Nasution, S. A. (2017). Model pembelajaran kolaboratif sebagai alternatif pembelajaran ilmu pengetahuan sosial. Didaktika Tauhidi : Jurnal Pendidikan Guru Sekolah Dasar, 4(1), 19-30. https://doi.org/10.30997/dt.v4i1.822

Tüzün, H., Bilgiç, H. G., \& Elçi, S. Y. (2019). The effects of 3D multi-user virtual environments on collaborative learning and social presence. International Electronic Journal of Elementary Education, 11(3), 221-231. https://iejee.com/index.php/IEJEE/article/view/746

Ulfa, I. S. K., Trapsilasiwi, D., \& Yudianto, E. (2018). Profil berpikir kritis siswa dalam menyelesaikan soal fungsi komposisi melalui model pembelajaran kolaboratif. Jurnal Didaktik Matematika, 5(1), 40-53. https://doi.org/10.24815/jdm.v5i1.9972

Umamah, M., \& Muassomah, M. (2020). Pembelajaran daring melalui teknik kolaboratif pada keterampilan menulis peserta didik di SMA Darul Qur'an Kota Mojokerto. ALSUNIYAT: Jurnal Penelitian Bahasa, Sastra, Dan Budaya Arab, 3(2), 88-100. https://doi.org/10.17509/alsuniyat.v3i2.24362 